sixteen years ago (probably infected 1900 to 1901), and the lady, although she has had slight trouble with the other eye at times, has now developed severe irido-cyclitis, notwithstanding that she has been living for many years in Canada, and could not have been re-infected.

We generally consider the eye lesions as a toxic phenomenon, and they bear no relation to the number of parasites present in the blood, or the severity of other symptoms. In the human cases recovery rapidly follows treatment by soamin in all but Rhodesian cases. There have been no post-mortem examinations at a time when any eye symptoms were present.

\title{
ON CLOSE VERSUS DISTANT ILLUMINATION FOR OPERATIONS
}

BY

ERnest E. Maddox, M.D., F.R.C.S. Ed.

BOURNEMOUTH.

A LITTLE addition which I have made to conjunctival forceps for operations on "after cataract," as well as for emergency night operations, has proved so successful that its description may be of interest to those who have not yet solved their illumination difficulties. It consists in attaching a tiny screened electric lamp to one limb of the forceps, half an inch from the gripping end. This attachment can be made with adhesive strapping, or, better still, by a very light metal clip or steel wire, into the curl of which an ordinary bulb from a child's flashlamp is so screwed as to illuminate the iris brilliantly, when the forceps are gripping the limbal conjunctiva. The connecting cord must be of a featherweight character, and it is a great convenience that the ordinary flash-lamp, sold in so many shops, will provide the electricity required. The grip of the forceps ensures a perfectly steady light, and maintains its distance from the cornea constant. This is better than the plan which has been tried hitherto, and rightly abandoned, of attaching an electric lamp to a discission needle. Is it not a mistake to attach a lamp to any cutting instrument held by the working hand, since the light not only moves with the instrument, but makes manipulation more cumbrous? When, however, the lamp is borne, as I recommend, by fixation forceps, none of these disadvantages apply, and, like the mouse which released the lion, this small expedient is able to solve all difficulties of illumination arising through the absence of an assistant.

It is for " needling" operations that the method is ideal, although it also greatly facilitates the removal of foreign bodies from the 
cornea. In iridectomies, and in cataract extraction, the conjunctival forceps are out of use during a part of the operation. Some other way of securing the continuance of the close illumination must therefore be found. There are three which I have employed so far :-

(1). A helper can hold the lamp on the same forceps, or on the end of a short rod, close to the eye.

(2). A lamp fastened to a light eyeglass "finger-piece" by a short flexible wire can be clipped on the patient's nose.

(3). A thin metal disc to which the lamp is attached by a short but flexible silver wire can be fixed by plaster just above the patient's other eyebrow, so as to allow the lamp to be placed in the most convenient position.

A simple calculation with inverse squares shows that, in the absence of a condensing lens, the cornea is more brightly illuminated by a lamp of 2 c.p. at the distance of half an inch than by one of over 1000 c.p. at the distance of a yard ; while with a condensing lens, we have to take into account the focusing of the filament on to one spot of the patient's retina by an approximately parallel beam of light which introduces an irritating element into the illumination quite out of proportion to its brightness.

Though distant lights may have advantages of their own, especially in large hospitals, some form of close illumination will, I think, repay a trial in view of the following advantages:-

(1). Greater economy.

(2). Greater portability.

(3). Greater kindliness to the patient's eye. A close light is diffused widely over his retina, with no possibility of the image of the filament being thereon.

(4). Increase of the surgeon's visual acuteness. The smallness of the patch of light on the patient's eye causes far less chemical waste in the surgeon's retina than a widespread shine from the whole face and pillow.

\section{ANNOTATIONS}

\section{Gunn's Dots}

Judging from the accounts given of this peculiar appearance of the retina in several recent text-books, there seems to have arisen some misunderstanding. The original description by the late Marcus Gunn appeared in the Trans. of the Ophthal. Soc. U.K., Vol. III, p. 110, 1883. The appearances there described occurred in one family, and are sometimes described as "Crick" dots, from the family name. Gunn described the condition as follows :-

"Very minute yellowish-white shining dots for some distance 